\title{
Clorinda Matto de Turner: El papel de la mujer entre tradición e innovación
}

\author{
MARIA M. CABALLERO WANGÜEMERT*
}

Entre los escasos estudios que abordan la actividad narrativa de la peruana Clorinda Matto de Turner ${ }^{1}$ es ya tópico resaltar el papel innovador desempeñado por su primera novela, Aves sin nido (1889), cuyo centenario hemos celebrado. Aves sin nido sería la obra que, más allá de su discutible calidad literaria, marcaría la inflexión en el enfoque del indio desde una exótica idealización propiciada por la lejanía geográfica y la distancia cronológica; hasta el tratamiento costumbrista o naturalista, que inevitablemente pondría sobre el tablero las injusticias sufridas por este ser milenario. Indianismo/Indigenismo giran en esta interpretación sobre el gozne de una novela cuya lectura resulta inexcusable.

La crítica haB"milatizado"cel excesirotentusiasmo, así como el indudable maniqueísmog de taleśsesèveraciones: Aves sin nido es una narración híbrida, teñida de romanticismo y concebida más como "breviario" pedagógico que como anatomía positivista ${ }^{2}$. En la misma

* Profesora del Departamento de Filologías Integradas (Literatura Hispanoamericana), Universidad de Sevilla.

${ }^{1}$ Augusto Tamayo Vargas, Guía para un estudio de Clorinda Matto de Turner, Lima, Turismo, 1945. Manuel E. Cuadros, Paisaje y obra. Mujer e historia. Clorinda Matto de Turner: estudio crítico-biográfico. Cuzco, Rozas, 1949. Francisco Carrillo, Clorinda Matto de Turner y su indigenismo literario, Lima, Biblioteca Universitaria, 1967. Antonio Cornejo Polar, Clorinda Matto de Turner: para una imagen de la novela peruana del XIX (En: Escritura, 1977, pp. 91-107; así como sus introducciones a la edición de Aves sin nido. La Habana, Casa de las Américas, 1974; Indole. Lima, Instituto Nacional de Cultura, 1974 y Herencia. Lima, Instituto Nacional de Cultura, 1974). María Milagro Caballero Wangüemert, Clorinda Matto de Tumer (En: Historia de la literatura hispanoamericana. Tomo II, Madrid, Cáredra, 1987, pp. 219-225).

${ }^{2}$ Cfr. Alfred Melon, Structure et estructures dans "Aves sin nido" de Clorinda Matto de Tumer (En: Le roman romantique latino-americaine et ses prolongements. Paris, 
línea se moverán sus dos novelas posteriores, Indole (1891) y Herencia (1895) que intensifican los presupuestos deterministas según los cuales el ambiente modela al individuo hasta robarle su libertad. Lima es ahora "la horrible" -como diría Salazar Bondy años después-, la ciudad corrupta en la que una burguesía viciada impide el desarrollo de las virtudes en las generaciones jóvenes.

No obstante, este enfoque, si bien engloba las tres novelas de la peruana, deja al margen el conjunto de tradiciones que bajo distintos títulos publicó a lo largo de su vida. Serán simples esbozos narrativos, ejercicios de principiante con los que se habría iniciado en la difícil tarea de la escritura de la mano de su maestro y amigo Ricardo Palma. Su carácter romántico-idealista los alejaría de las preocupaciones y posterior trayectoria de la peruana.

Me propongo sostener aquí la invalidez de tal planteamiento. Una misma inquietud moral sustenta las diversas actividades literarias de Clorinda, desde la tradición hasta la novela cuasi naturalista, sin olvidar su ininterrumpida actuación en el periodismo. Es más, pienso que en el periodismo está la claye aglutinante de toda su obra, no sólo por la elevada concepción de su ministerio -"sacerdocio de la enseñanza" llega a denominarlo- sino también por la constancia de su dedicación: la Matto se inicia en los periódicos de su ciudad natal -El Heraldo, El Ferrocarril, ÉEEé de los Andes..; funda y dirige El Recreo del Cuzco en Lbraledeur76; postetiormente lleva la jefatura de redacción de La Bolsa, de Arequipa y sobre todo de El Perú Ilustrado (1889-1892), órgano difusor de sus veladas que le permitirá propagar las doctrinas de pensadores con la relevancia social de un González Prada o introducir en sociedad a escritores noveles como el entonces jovencísimo Darío. Su actividad en este sentido no decae jamás; incluso muchos años después en el exilio argentino lanzará un nuevo periódico, El Búcaro Americano, símbolo de su pasión por el tema.

Desde este punto de vista hay que considerar que nuestra escritora escribe con la urgencia de la crónica periódica, lo que le impide

L'Harnattan, 1984, pp. 277-301). Comparto el enfoque del profesor Melon en cuanto al hibridismo narrativo, el didactismo y la herencia romántica. Por el contrario, encuentro algo exagerada la valoración global de la obra que, en mi opinión, adolece de fallas estructurales propios de un autor novel. 
tal vez matizar estilísticamente sus artículos; pero también con acentuada conciencia de su elevada misión. El periodismo se ha convertido en la nueva religión laica, “...es el llamado a instruir las diversas porciones de la sociedad, y también predicar por doquiera la moral y las virtudes laicas"; [es depositario de una] "sagrada misión [cuyo] objeto principal debe ser el bien de la humanidad"3. Esa inquietud éticopedagógica resulta patente en sus opiniones sobre el estado del país maltratado por la guerra con Chile; sobre la situación del indio oprimido por un lastre de siglos; sobre la misión de la Iglesia, prostituida por algunos representantes indignos; sobre el comportamiento corrupto de la sociedad peruana y limeña en particular... Clorinda emprenderá desde sus primeros años una cruzada periodística apoyada en la ideología del progreso que -según ella-deberá combinarse con los sólidos valores tradicionales reducidos a grupos minoritarios en su época. En los primeros artículos están en germen las tesis que desarrollará en sus tres novelas y en algunas de sus tradiciones. Me gustaría citar como ejemplo su opinión sobre la mujer, plasmada en el artículo "La mujer,

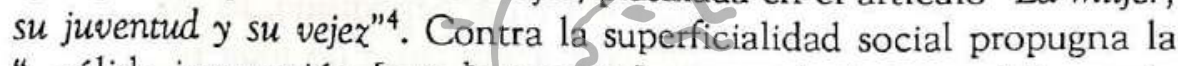
"...sólida instrucción [que le permita] poner el cimiento del grande edificio moral en el corazón de los hijos, cuya primera educación le está confiada; [misión de la que] depende la felicidad de toda una sociedad". Sin llegap a ser "sabias despreocupadas" de esa tarea fundamental, es importante una cultura que yayaomás allá del "peinar cabecitas, coser batitas de ingenio, y cuidar que el niño tome el alimento, [porque] la superficialidad en la educación de la mujer es una de las causas del disgusto prematuro que se apodera de los maridos"6.

${ }^{3}$ Clorinda Matto de Turner, El periodismo (En: Tradiciones cuzqueñas. Leyendas, Biografías y hojas sueltas. Tomo 1. Arequipa, Imprenta de La Bolsa, 1884, p. 222). A partir de ahora citaré por esta primera edición que se completa con Tradiciones curqueñas. Crónicas. Hojas sueltas. Torno II. Lima, Imprenta de Torres Aguirre, 1886. Ambas serán utilizadas como base textual de este artículo. 245-248.

${ }^{4}$ Recogido en Clorinda Matto de Turner, Tradiciones... Tomo 1, op. cit., pp.

${ }^{5}$ Ibidem, p. 246.

${ }^{6}$ Ibidem, p. 246. Un par de años después reitera idéntico mensaje en Para ellas (En: Tradiciones. Tomo II, op. cit., p. 160: "La instrucción es el precioso talismán que la mujer lleva en sí misma contra las puerilidades que, abundando en doloroso número, han llegado a invadir hasta el corazón del sexo llamado fuerte.

La instrucción ha declarado la guerra a la necedad". 
Adalid de la independencia cultural de la mujer, al apostar por un trabajo que la enriquezca no olvida su papel insustituible como madre. Respecto de este asunto, obsérvese la similitud de pensamiento entre sus palabras de 1884 y el siguiente diálogo mantenido por dos personajes de su última novela, Herencia (1895):

- ¡Ah doctor! ¡Es el todo! el ejemplo del hogar importa para mí toda la doctrina de moral social.

- Cabales. Por eso las esposas y las madres libidinosas dejan a las hijas la herencia fatal...?

Los años y la progresiva introducción del naturalismo zolesco a través de las tertulias literarias y la actividad de mujeres como Juana Gorriti y Mercedes Cabello de Carbonera han teñido con matiz determinista -biológico y educacional- el plantemiento de Clorinda. $\mathrm{Y}$ es que, sin olvidar el periodismo, ahora la novela es para ella "...ins-

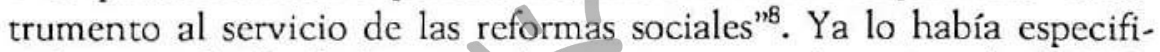
cado, a modo de declaración de principios, en Aves sin nido (1889), su primera obra narrativa: "La noyéla tiene que ser la fotografía que estereotipe los vicios y virtudes de un pueblo, con la consiguiente moraleja correctiva para aquellos y el homenaje de admiración para éstas"'. Respecto de este asunto, no hay solución de continuidad entre las dos obras citadas, como lo prueban las palabras del narrador de Indole (1891):

Nadie sino el novelista observador que llevando el correctivo en los puntos de su pluma, penetra los misterios de la vida, y descorre ante la multitud ese denso velo que cubre los ojos de los moradores ciegos y fanatizados a un mismo tiempo. ${ }^{10}$

Nadie sino él tiene el poder y el deber, a la vez, de denunciar las lacras sociales y proponer soluciones; aunque Clorinda se queja amargamente de que ese tipo de "novela trascendental [...] no tiene ni prosélitos ni cultivadores"11. En esos presupuestos se funden dos vías

${ }^{7}$ Clorinda Matto de Turner, Herencia. Ed. de Cornejo Polar ya citada, p. 114.

${ }^{8}$ Cfr. Mario Castro Arenas, Clorinda Matto de Turner y la novela indigenista (En: La novela peruana y la evolución social. Lima, Cultura y Libertad, 1965, pp. 105-112.

${ }^{9}$ Clorinda Matto de Turner, Aves sin nido. Ed. de Cornejo Polar.

${ }^{10} \mathrm{Ibidem}$, Indole. Ed. de Cornejo Polar ya citada, p. 250.

${ }^{11} \mathrm{Ibidem}$, p. 250. 
complementarias: el personal didactismo romántico, muy fuerte en la peruana; y las nuevas orientaciones literarias, deudoras de Stendhal y Zola... La primera tiene una entidad que va más allá de modas y que sirve como aglutinante de su preocupación por la patria, sus opiniones sobre la Iglesia y los sacerdotes, así como su celo por el indio; temas todos ellos presentes en mayor o menor proporción en crónicas periodísticas, tradiciones y novelas.

Me gustaría contemplar las Tradiciones cuzqueñas en este amplio marco y no exclusivamente como género específico. Por otra parte, no es habitual encontrar estudios monográficos sobre las tradiciones. Manuel Cuadros, por ejemplo, aborda su descripción externa -temas, argumentos...- dentro del estudio global de su obra y sin profundizar en su sentido o emitir juicio alguno sobre su valía ${ }^{12}$. Margaret Campbell, por el contrario, dedica un pequeño artículo a su estudio exclusivo ${ }^{13}$ : tras esbozar el contexto biográfico de la Matto pasa a ilustrar el magisterio de Palma y definir la tradición; para culminar con un breve análisis comparativo en el que los baremos de fuentes, humor, riqueza léxica favorecen claramente al maestro. El resto de la crítica trata superficialmente unas tradiciones que desde la óptica palmiana siempre serán deficitarias para la Matto por la distancia de caracteres y propósitos entre ambos escritores. En realidad, lo que Clorinda publicára bajol ese nómbre es una miscelánea que recoge su actividad p̧etiodísticall Laoconaprobación es muy clara para el segundo volumen (Lima, 1886), cuyos textos corresponden casi en su totalidad a La Bolsa de Arequipa durante $1885^{14}$. Pero además la organización tripartita de ese material -Tradiciones cuzqueñas.Crónicas. Hojas sueltas- no está realizada con un criterio estricto; los límites genéricos, por así decir, no están perfilados y la nomenclatura no se ajusta con objetividad al contenido. Adjunto un cuadro que permite comprobar este aserto:

${ }^{12}$ Cfr. Manuel E. Cuadros, Paisaje..., op. cit., pp. $62-89$.
${ }^{13}$ Cfr. Margaret V. Campbell, The "Tradiciones cuzqueñas" of Clorinda Matto de Turner (En: Hispania, 42, Diciembre de 1959, $\mathrm{N}^{\circ} 4$, pp. 492-497):

${ }^{14}$ En realidad la primera tradición recogida es de 20 de diciembre de 1884 y las dos últimas corresponden ya a las colaboraciones en la Revista Social de Lima durante 1886 . 
Tradiciones

- Un doble y un repique.

- Las tres hermanas.

- Caer a hora.

- Pobre importuno saca mendrugo.

- Chico pleito.

- Azotaina mayúscula.

- De cabildo a cabildo.

- Buena laya de hombre.

- ¿La del arzobispo?

- El risco de Yaya-Huarcusca.

- Plagas humanas.

- Ccatta-hueqque. (Leyenda).

- Llamada de sepulcro.

- Moscas y moscardones.

- De llama y fuego.

Crónicas

- Crónica deHós córégidores quẹ gobernaron en el Cuzco de 1661 a 1749.orge Puccinelli Converso»

Hojas sueltas

- Sonrisa de Dios.

- La romería de Caima.

- Nocturno.

- La quena. (Leyenda).

- La corona blanca.

- En la paz de Dios.

- Malccoy. (Leyenda).

- Entre dos luces.

- Armonías.

- Entre las sombras.

- Getsemaní. 
- ¡Alleluia!, alleluia!

- Música y amor.

- Entre las tumbas.

- Para ellas.

- Las artistas

- Remembranzas.

- San Cristóbal.

- Amor de redondel.

- En lontananza.

- En la tormenta.

- El oráculo del indio. (Leyenda).

Si se deja a un lado la crónica, ajena a nuestro interés actual y se admite $a$ priori que las tradiciones son tales, según el concepto acuñado por Palma -cuestión que perfilaré después-, restaría el conjunto de Hojas sueltas, conjunto periodístico en el que cabría establecer varios niveles:

1. Recuerdos autobiográficos - La corona blanca, Entre las sombras, Remembranzas- interesantes para definir su personalidad y reconstruir los avatares ] dẹ ota agitalda lexistencia. Los dos últimos aluden, dentro de las cogrdenadasedelGretoricismo romántico, a una vida desgraciada: la muerte del marido que inicia la quiebra económica agigantada por administradores ambiciosos y la impotencia de Clorinda en su lucha contra la dureza de la tierra volcánica... Esta es símbolo de nuevas invasiones: "la filosofía materialista; lava volcánica que cayendo sobre el corazón humano estiriliza los más dulces sentimientos"15 y "Chile, esa aguda lengua de tierra [que] pregonó la ira de Luzbel"16. La invasión chilena desata la preocupación y el lamento por la patria avasallada, a la vez que empuja a la militancia activa en su ayuda a Cáceres. En El oráculo del indio, por ejemplo, negros presagios acaban convirtiéndose en la funesta realidad que vivió Clorinda: cit., p. 140 ).

${ }^{15}$ Clorinda Matto de Turner, Entre las sombras (En: Tradiciones. Tomo Il, op. ${ }^{16}$ Ibidem, p. 141. 
Campos desolados, casas enlutadas, rostros demacrados por el hambre, la ruina y la pobreza por doquiera: esa era la reseña de las calamidades que sembró la guerra del Pacífico. ${ }^{17}$

Contrasta en estas páginas el desmelenamiento romántico de la forma-exclamaciones, interrogaciones retóricas, el marco nocturno y sepulcral...- con la resolución estoica de la peruana que se traducirá vivencialmente en la lucha incansable por volver a comenzar desde el campo intelectual y el periodismo. He aquí un ejemplo de lo que digo:

¿Quién ha de detener nunca su mente para contemplar a la pobre mujer solitaria, huérfana y errante que, sin asilo, se lanza en un mundo semejante al océano embravecido?

Su juventud inspira solo codicia.

Su desolación acaso indiferencia.

Y tras esbozar su propia odisea concluye:

Hemos sufrido, hemos aprendido. ${ }^{18}$

2. Apuntes de viaje, muy del gusto romántico, en los que la anécdota personal es una mera excusa para reflejar el entorno peruano y sus costumbres: La romería a Caima, En la paz de Dios, San Cristóbal, En lontananza, En la tormenta y Nocturno. Me interesa éste último por su título muy del momento recuérdese Tos famosísimos de José Asunción Silva pero sobre tođø por lfáatmósfera premodernista que destila en sus dos primeras páginas:

El hastío es el cansancio del alma en el penoso viaje de la vida.

El nublado es el hastío de la naturaleza. [...]

¿Quién no se ha sentido con el alma oprimida en los días de hastío?

${ }^{17}$ Clorinda Marto de Turner, El oráculo del indio (En: Tradiciones, Tomo II, op. cit., p. 193). Por cierto que la técnica del presagio recuerda la utilizada por Andrés Bello en sus Silvas americanas. Dice Clorinda: “...presagiando, consternado, horribles cosas para la patria y para mi familia [...] que todo va a caer con sangre y duelo. Attoc-hillapa ha aullado como grande, y el cernícalo ha arrebatado la paloma blanca que, inocente, posaba sobre el campanario del pueblo", p. 192. p. 169).

${ }^{18}$ Clorinda Matto de Turner, Remembranzas (En: Tradiciones. Tomo II, op. cit., 
Todos: ya tristes en los momentos de recuerdo, ya enloquecidos en las horas de lucidez, vagamos durante un año, diez, veinte años, pasando por entre escombros y ruinas que en su áspero laberinto hieren la planta hasta que un día ha brotado sangre, esa sangre del alma, que en lluvia cristalina inunda la mejilla aligerando el corazón... ${ }^{19}$

La angustia, el hastío... herirán a los modernistas configurando la crisis finisecular. Pero hay algo que los separa abismalmente de los románticos: la inseguridad, la pérdida de la fe... No hay más que recordar el célebre y programático Prólogo al poema Al Niágara de José Martí. (1882):

A todos besó la misma maga. En todos está hirviendo la sangre nueva. Aunque se despedacen las entrañas en su rincón más callado están airadas y hambrientas la Intranquilidad, la Inseguridad, la Vaga Esperanza, la Visión Secreta. Un inmenso hombre pálido de rostro enjuto, ojos llorosos y boca seca, vestido de negro, anda con pasos graves, sin reposar ni dormir, por toda la tienra $[\ldots . .\}_{i} Q u e ́$ no saber lo que se desea!... ${ }^{20}$

A solo tres años de estas palabras martianas aplicables a su generación Clorinda continua anclada en la fe: "la naturaleza nos habla de dios" -dice como buena romántica ${ }^{2}$-et "No podemos convenir en la existencia del ateo, pues no creemos haber llegado al siglo de los hombres descorazonados ${ }^{2}$. Opinión contradicha por toda una legión de excelentes escritores que renovarán las letras del continente. En ese sentido la peruana fue una rezagada que no llegó ni siquiera a atisbar la revolución contemporánea, a pesar de haber introducido a Darío. Su pedagogía, su didactismo - de manifiesto una vez más en su crónica sobre Los artistas ${ }^{23}$ - son incompatibles con esos “...cánones del arte moderno [que] no nos señalan más derroteros que el amor absoluto a la belleza -clara, simbólica o arcana- y el desenvolvimiento y 110).

${ }^{19}$ Clorinda Matto de Turner, Nocturno (En: Tradiciones. Tomo II, op. cit., p. 109.

${ }^{20}$ José Martí, Prólogo al poema Al Niágara (citado por Ricardo Gullón, El modernismo visto por modernistas. Madrid, Guadarrama, 1980, pp. 35-36).

${ }_{21}^{11}$ Clorinda Matto de Turner, Noctumo (En: Tradiciones. Tomo Il, op. cit., p. 112).

${ }^{22}$ Ibidem, p. 110.

${ }^{23}$ Recogida en Tradiciones, Tomo II, op. cit., pp. 163-165. 
manifestación de la personalidad"24. Más aún: constituyen el polo opuesto del programa del nicaragüense:

En verdad vivo de poesía [...] Amo la hermosura, el poder, la gracia, el dinero, el lujo, los besos y la música. No soy más que un hombre de arte...

3. Del resto de crónicas me gustaría rescatar dos bloques: las de tema religioso y aquellas otras que giran sobre tradiciones y costumbres indígenas. Las primeras glosan la Cuaresma cristiana desde Carnaval -Entre dos luces- hasta la Resurrección del Señor -iAlleluia, alleluia!- pasando por la Semana Santa-Armonías y Getsemaní-. Estas páginas destilan piedad y acendrados sentimientos cristianos dentro de la más exquisita ortodoxia. Creo pertinente destacarlo para hacer ver cómo el intenso anticlericalismo de sus novelas -patente sobre todo en Indole - es una crítica parcial a los indignos ministros de la religión católica y, en segundo lugar, a la exigencia del celibato para ellos $^{26}$. Es, por tanto, una cuestión de jerarquía y costumbres más que de fe... Así Clorinda vuelve de nuevo a encasillarse en el ambiente decimonónico ${ }^{27}$.

Respecto al asunto del indio, los tres artículos que lo tocan $-L a$ quena, Malccoy y El oráculo del indio= son una excrecencia de las le-

${ }^{24}$ Rubén Darío, Los colores del estandarte (cirado, por Ricardo Gullón, El modernismo..., op. cit., p. 55).

${ }^{25} \mathrm{Ibidem}, \mathrm{p}$. 51. La originalidad de la prosa modernista está igualmente a años luz de la decimonónica expresión de Clorinda.

${ }^{26}$ Incomprendido siempre por Clorinda quien en este aspecto se mueve en las coordenadas del fisiologismo determinista. Cfr. al respecto las palabras del prólogo de Aves sin nido: "¿Quién sabe si se reconocerá la necesidad del matrimonio de los curas como una exigencia social?". Ed. cit., p. 2. Por otra parte las tradiciones incluyen esporádicos "pullazos" contra el sentido de la vida en clausura: "Cuantas virtuosas familias arrancadas al seno de las sociedades, tal vez preciosas ilusiones marchitas al nacer, y asesinadas para encerrar sus despojos en el ataíd de los vivos!" Santa Catalina de Arequipa (En: Tradiciones. Tomo I, op. cit., p. 42). No obstante, el alegato se reparte por igual contra las monjas iluminadas del Siglo de Oro (Cfr. La mala Carranza. Tradiciones, Tomo 1, op. cit., pp. 65-66), y "...la carcoma del siglo llamado con énfasis filosofía alemana". (La Virgen de los Remedios. Tradiciones, Tomo I, op. cit., p. 111).

${ }^{27}$ Como es sabido, este ambiente se define por un anticlericalismo exacerbado en el que sobresalen los realistas y naturalistas de la época. Novela paradigmática, $\mathrm{La}$ regenta de Leopoldo Alas "Clarín" aborda con exquisitez simbolista un asunto que en las novelas de Clorinda se plantea en términos más burdamente naturalistas. 
yendas publicadas en el primer volumen de Tradiciones cuzqueñas; y en este sentido no existe razón alguna para situarlas dentro del cajón de sastre de Hojas sueltas, como no sea su corto número. En consecuencia voy a analizarlas junto a las cinco del primer volumen, añadiendo dos más publicadas como tradiciones, que no son tales: Un diablo tísico (1er. vol.) y Ccatta-hueqque ( $2^{\circ}$ vol.).

Convendría decir, antes de seguir adelante, que el primer volumen al que hago referencia se publica en 1884 con la siguiente distribución: 39 tradiciones, 6 leyendas, 6 biografías, 11 hojas sueltas. Me parece innecesario insistir en el análisis de estas últimas ya que no aportan ninguna novedad sobre lo visto hasta aquí. Tal vez reseñar que incluyen un yaraví: Sillquihua, cuya recolección adelanta la labor antropológica de un Jose María Arguedas, por ejemplo. Clorinda conocía "...el inimitable quichua, cuya dulzura de expresión aumenta el interés de cualquier relato" ${ }^{\prime 2}$, pero sobre todo aporte lingüístico configurante de la nacionalidad peruana, según ella. En cuanto a las biografías, se mueven en los parámétros de lo hagiográfico al exaltar a sus contemporáneos de los que nunca vivió aislada. Lo prueban las constantes referencias a su tiempo, el de la república y sus males, la inquietud por la patria que atraviesa momentos difíciles... Esta militancia activa pasa por el compromiso y le reportará el destierro, lo que muestra que nibse tratac de huera retónica. Las biografías son,

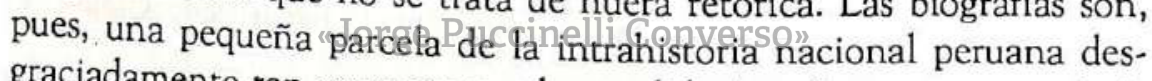
graciadamente tan concreta que ha perdido interés para nuestra óptica de lectores del siglo xx. Vuelvo por tanto, a las leyendas sobre el indígena englobando en $\mathrm{mi}$ análisis ese pequeño corpus de diez textos.

En algunos casos la historia surge con naturalidad como respuesta a la búsqueda de costumbres y elementos legendarios llevada a cabo por la peruana ${ }^{29}$. Es lo que sucede en Cchaska o La quena: ambas responden al tópico romántico entre india y mestizo, o blanco e india. Detrás, como soporte de este tipo de narraciones, se encontrará la

${ }^{28}$ Clorinda Matro de Turner, Cchaska (En: Tradiciones, Tomo I, op. cit., p. 177). al castellano de José Sebastián Barranca y su versificación por Constantino Carrrasco reforzaron ese interés por las costumbres quechuas. 
novela indianista -así denominada por Concha Meléndez ${ }^{30}$ - que se apoya en obras como Los incas (1777) de Marmontel y en la visión utópica del indio propia de los ilustrados franceses. En 1879 había aparecido Cumandá, del ecuatoriano Juan León Mera, obra paradigmática del género... y en 1888 el uruguayo Juan Zorrilla de San Martín publicará en París su famoso Tabaré. Tema de época, en el Perú había sido abordado por escasas tradiciones de Ricardo Palma, entre las que destaca Palla-Huarcuna (1860) -en ella, la evasión de los amantes, como en Cchaska, desemboca en la muerte-; por Carlos Augusto Salaverry y Ricardo Rossell en drama y poesía, respectivamente. Tanto este último -que escribe los poemas Hima-Sumac (1877) y Catalina Tupac-Rocca (1879) - como Manuel González Prada coincidirán con la Matto de Turner en la tertulia del Ateneo de Lima ${ }^{31}$.

En resumen, influjos y matices divergentes desde la idealización romántica al realismo cuasinaturalista, que se van a ver reflejados en las leyendas de la peruana. Cuatro de ellas - Un diablo tísico, Frailes, La peña del castigo y Ccata-hueqque- surgen para dar razón histórico-legendaria de una topografía cercana al Cuzco... Una piedra, roca o rincón abrupto tiene a sus espaldas una leyenda que la Clorinda "revolvedora de antiguallas" pero sobre todo vecina de la tierra transmitirá. EB iel céntro jcómo ne! una anécdota amorosa enfrenta a una india ingcente, bella yiel fon un blanco traicionero y arrogante de los que "se arrastran como reptiles, para alzarse después como tiranos" ${ }^{132}$. El resultado es siempre nefasto: la enajenación y posterior suicidio en Cussiccoillor; la muerte de ambos amantes a manos del pariente indígena que vengará así la deshonra familiar en Frailes, pero que también puede dar la salvación cuando la naturaleza

${ }^{30}$ Cfr. Concha Meléndez, La novela indianista en Hispanoamérica. Río Piedras, Puerto Rico, UPREX, 1961.

${ }^{31}$ Cfr. al respecto Augusto Tamayo Vargas, Literatura peruana. Tomo II. Lima, Universidad Nacional Mayor de San Marcos, 1965.

${ }^{32}$ Clorinda Matro de Turner, Cussiccoillor (En: Tradiciones. Tomo I, op. cit., p. 152). Hay varias referencias en este sentido: "los vicios de los blancos" (Frailes. Tradiciones, Tomo 1, op. cit., p. 160) que se disculpan "con la facilidad propia de los blancos" (La peña del castigo. Tradiciones. Tomo I, op. cit., p. 168). "Las indias [por el contrario] arnan una sola vez y son fieles como el perro de largas lanas que siempre sigue las huellas de tu pie". (Frailes. Tradiciones. Tomo 1, op. cit., p. 161). 
se venga del blanco, como en La peña del castigo ${ }^{33}$. En ese mundo arcádico inmediatamente posterior a la conquista en que están situadas la mayoría, el blanco ha introducido la destrucción y la decadencia, hasta el punto de que "... el cautiverio ha hecho dejenerar [sic] la raza indígena dejando caer denso velo sobre sus cualidades intelectuales....134. Clorinda rinde culto a ese determinismo biológico que exaltarán después Carlos Octavio Bunge en Nuestra América (1904) y Alcides Arguedas en Pueblo enfermo (1908). Aunque panfletaria y retórica en ocasiones, de aquí se desprende su sincera indignación ante el sufrimiento del indígena oprimido secularmente por la raza conquistadora. Las referencias son constantes, casi abrumadoras, a veces diluidas en el desarrollo de alguna tradición, por ejemplo, De cima de horca:

Holgado quedóse petrificado repasando su conciencia para recordar alguna buena acción ejercitada con la desventurada raza indígena.. ${ }^{35}$

pero exhaustivamente como excurso del narrador que toma parte en la historia con cierto tremendismo retórico y parcial compadeciéndose de una situación tributaría de la conquista:

La codicia tomó mayores proporciones y los indios acrecían los dobrè sécretosede su cautiverio, porque esa voz de oro era

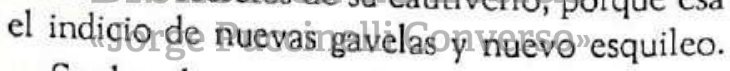

Se deseaba oro para S.M. el rey.

Se pedía oro para socorrer las cortes.

Y el indio debía sacarlo del seno de la tierra o del fondo del sepulcro ${ }^{36}$.

${ }^{33}$ Aquí la temática tiene un curioso parecido con la de su propio drama drama la india también es sacrificada.

${ }^{34}$ Clorinda Matto de Turner, Malccoy (En: Tradiciones. Tomo II, op. cit., p. 125). famoso viaje. cit., p. 60).

${ }^{35}$ Clorinda Matto de Turner, De cima de horca (En: Tradiciones. Tomo I, op.

${ }^{36}$ Clorinda Matto de Turner, La peña del castigo (En: Tradiciones. Tomo I, op. cit., p. 167). Idéntico es el mensaje de Vaya un decreto, en la p. 26. 
El tema es reiterativo: "los indios que en amargo mutismo soportan las calamidades que la mano del blanco les brinda" ${ }^{\text {"37 }}$ y se extiende a las tradiciones que no tienen por eje el asunto indígena, lo que prueba la tesis inicial de mi trabajo: Clorinda vierte una y otra vez sus preocupaciones, vengan o no a cuento. Aunque es obvio, parece oportuno resaltar que el indio altivo, exótico y lejano de tiempos de la conquista ha dado paso al ser humilde, parte integrante de "...aquellos huérfanos, que desde entonces perdieron padre, patria y libertad para entrar en cautiverio..." ${ }^{38}$. El mensaje de denuncia es exacto al que reiterará en Aves sin nido:

Que iban ha [sic] hacer los indios!!

Juntáronse en manada, al capricho de la fortuna.

Para eso era el indio, el ganado del esquileo del corregidor, el cura, el alcalde y todo ser que manejaba la vara de mandato ${ }^{39}$.

Idéntica asimismo es la petición de una reforma radical que alcance las capas más profundas del Perú... Entre la ironía y la esperanza sus palabras traducen íntimas dudas al respecto:

Al indio no le queda más refugio que sus lágrimas, por injusticia semejante.

¿Ni quich ha de fmejoraflo? etras

¡Espéremos? quequalilìnadministración del Perú tiene más esperanzas que un ahorcado: ya llegará su tiempo: entretanto cerremos capítulo que puede traernos cara feira de parte de quienes no soportan interrogatorio. Son tiempos de libertad; cada uno hace lo que quiere y mejor es volver a lo viejo anudando relato ${ }^{40}$. 184).

${ }^{37}$ Clorinda Matto de Turner, Cchaska (En: Tradiciones. Tomo 1, op. cit., p. p. 58).

${ }^{38}$ Clorinda Matto de Turner, Ccatta-hueqque (En: Tradiciones. Tomo II, op. cit.,

${ }^{39}$ Clorinda Matto de Turner, El santo y la limosna (En: Tradiciones. Tomo I, op. cit., p. 131). Como es sabido, junto a su preocupación vivencial Clorinda recoge parte de estas ideas de dos novelas: El padre Horán (1848), de Narciso Aréstegui; y La trinidad del indio (1885), de José Itolarrares.

${ }^{40}$ Clorinda Matto de Turner, Plagas humanas (En: Tradiciones. Tomo II, op. cit., p. 55). Esta idea, algo desdibujada, preside también el proemio de Aves sin nido. 
Del costumbrismo y exotismo románticos a la denuncia. En esta línea ideológica es indudable el papel precursor de Clorinda Matto de Turner apoyada en González Prada y algunos otros, que no quedaría -como se ha visto- para una novela antológica, sino por el contrario cohesionaría la tarea de toda una vida. Porque en su "deseo de estructurar un elemento para cultura autóctona" ${ }^{\prime 11}$ sus textos enfocan más desde una función pedagógica cercana a la eclesial de la primitiva colonización, que como propuesta en términos de mercado económico, lo que harán los indigenistas del xx inspirándose en Mariátegui. No hay más que ver el papel que lą narradora se atribuye en Malccoy, apadrinando las bodas de los dos enamorados ${ }^{42}$. Pero además es una literatura escrita por blancos y para blancos desde un foco externo que superarán muchos años después los indigenistas. $\mathrm{Al}$ respecto basta comparar la visión que del Cuzco nos da la Matto en Recordando ${ }^{43}$ con la de un Jose María Arguedas en el primer capítulo de Los ríos profundos... Por ello, tanto las alabanzas como las críticas que se han hecho a Aves sin nido pueden hacerse extensiva a Ios textos aquí examinados, híbridos de "...costumbrismo, romanticismo y realismo [que] no son, en el caso peruano, más que modalidad de un solo sistema literario “como ha dicho Cornejo Polar 44 . No debe extrañar cierto pesimismo de fondo en un momento de pleno auge naturalista -en 1884, por ejemplo, Zeno Gandía publica La chatcafunal de lastgrandes novelas de la escuela en Hispanoaméricąe.Pero ese pesimístho no impide pasar a la acción a nivel individual y colectivo; como se comprueba por ser el Cuzco cuna de los movimientos reivindicatorios a favor del indio...

Vamos, finalmente, al análisis de las tradiciones que constituyen parte de ese amplio corpus que se extiende por toda Hispanoamérica

${ }_{41}^{41}$ Augusto Tamayo Vargas, Literatura..., op. cit., p. 523.

${ }^{42}$ Cfr. Clorinda Matto de Turner, Malccoy (En: Tradiciones. Tomo II, op. cit., p. 130). Por cierto que esos amores entre adolescentes serranos adelantan los que recogerá Ciro Alegría en Los perros hambrientos. También aparece ya esa constante intervención del narrador en el texto para explicar costumbres de la sierra a los lectores limeños, lo que se adecúa bien al concepto de "literatura heterogénea" acuñado por Cornejo Polar.

pp. 239-240).

${ }^{43}$ Cfr. Clorinda Matto de Turner, Recordando (En: Tradiciones. Tomo 1, op., cit.,

${ }^{44}$ Antonio Cornejo Polar, Introducción a Indole, ed. cit., p. 11. 
bajo la sombra del maestro Palma -como ha recordado Estuardo Núñez ${ }^{45}$. El primer problema radica en su definición acuñada por el mismo Palma después de años de tanteo: "Estilo ligero, frase redondeada, sobriedad en las descripciones, rapidez en el relato, presentación de personajes y caracteres en un rasgo de pluma, diálogo sencillo a la par de animado, novela en miniatura, novela homeopática, por decirlo así, es lo que en mi concepto, ha de ser la tradición"46. Definición compleja y escurridiza en la que no caben la mayoría de los imitadores que se apoyan en la intrahistoria lejana y amable para esbozar una anécdota carente de interés. El "puntal" de Palma es su lenguaje difícilmente exportable, en cuanto que su "mimetismo arcaizante y popularizador" -como diría Martinengo ${ }^{47}$ - es fórmula única apoyada en una gracia limeña muy particular que no ha envejecido. Precisamente la mayor parte de los críticos achacan a la Matto el no haber conseguido un lenguaje cuya frescura mantenga ágil la tradición al cabo de los años. En ese sentido, la tradición, sin alcanzar la categoría de "género nuevo", es algo más que un mero cuento "...cuya característica más saltante es su retrospeccional pasado" ${ }^{48}$. Ese pasado debe tamizarse con una leve pero sostenida ironía, reflejo de su chispa criolla. Justo lo que falta a Clorinda en su deseo de “...seguir al maestro Palma; [...] en realidad estaba distante de él en gracia, en la picardía criolla de don Ricardo. Clorinda Matto ofrecía narraciones históricas de interés local; sencillas, es cierto, pero faltas de gracia original"49.

En resumen, ironía y lenguaje "como norma literaria cuyo paradigma es la oralidad" 50 . Y al fondo "la colonia como síntoma"-

${ }^{45}$ Cfr. Estuardo Núñez, El género o especie "tradición" en el ámbito hispanoamericano (En: XVII Congreso del Instituto Internacional de Literatura Iberoamericana. Tomo III. Madrid, ICI, 1978, pp. 1469-1474).

${ }^{46}$ Ricardo Palma, Tradiciones peruanas completas. Madrid, Aguilar, 1964, p. 1474.

${ }^{47} \mathrm{Cfr}$. Alessandro Martinengo, El estilo de Palma: mimetismo arcaizante y mimetismo popularizador (En: Origenes del cuento hispanoamericano (Ricardo Palma y sus tradiciones) México, Premià, 1979, pp. 55-60).

${ }^{48}$ Estuardo Núñez, El género..., op. cit., p. 1469. En absoluto estoy de acuerdo con esta opinión ya que me parece que un determinado lenguaje es ingrediente fundamental en la tradición, que le separa de la leyenda romántica procedente de Scott.

${ }_{50}^{49}$ Augusto Tamayo Vargas, Literatura..., op. cit., p. 546.

50 Alberto Escobar, Tensión, lenguaje y estructura: las Tradiciones peruanas. Lima, Universidad Nacional Mayor de San Marcos, 1962, p. 40. 
dice Oviedo- porque evocarla "...era dar en la yema del gusto a este pueblo que, libre, se debatía en la anarquía y que, sojuzgado, fue próspero y famoso"s1. ¿Involucionismo? Melancolía nostálgica, pero también positivo "deseo de encarar realidades, pequeñas realidades que conforman, explican y definen a un país" ${ }^{\prime 2}$.

¿Qué hay de todo esto en Clorinda? En primer lugar, la retrospección a la Colonia que, a pesar de todo, sigue siendo predominante. Incluso algunas tradiciones como La del arzobispo en las que la peruana se desdobla en narrador y personaje, terminan por remitir a la cronología y el mundo de la Colonia para explicar costumbres cuyas consecuencias perduran en la República. En muchos casos, igual que sucedía en los artículos periodísticos, se monta la tradición para dar cuenta de un topónimo - Arco punto y su cruz-, relatar la fundación de un monasterio - Santa Catalina de Arequipa o Santa Catalina de Cuzco-o justificar la fama de una casa siniestra -Tambo de Montero... Desde mi punto de vista son simples esbozos de tradiciones abortadas de raíz ya que la historia carece prácticamente de desarrollo, concentrada en escuetos párrafos que dan razón del suceso históricolegendario. El tono directo no tiene nada que ver con el relativismo irónico de Palma y se echa de menos ese sabroso lenguaje apoyado en el refranero populas idellaotierras. Degraciadarmente de las 36 tradi-

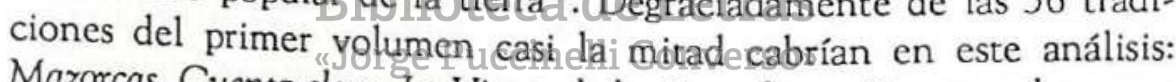
Mazorcas, Cuenta clara, La Virgen de los Remedios, y Fue un milagro por ejemplo, fallan porque el soporte narrativo es demasiado leve y mal estructurado; pero sobre todo debido a que lo que pudo esconder su punta de eficaz ironía, en la peruana se ha convertido en alegato: contra el abandono del tesoro artístico cuzqueño, contra la filosofía del siglo ... cualquier tema de actualidad. A veces, y esto es claro en la última tradición citada, se demora en el marco introductorio deleitándose como narradora en el planteamiento de la tradición al estilo de Palma: 
Llegan épocas en las que los sucesos caen como granizo haciendo suspirar al prójimo con el refrancico aquel ares o no ares, renta me pagues [...] Así el gobernador como alcalde o alguacil, todos se empeñan en aligerar la fortuna del infeliz que obedece en los tiempos republicanos donde nadie se conforma con ser pueblo y todos aspiran a mandatario... ${ }^{54}$

Aunque la crítica a la situación del momento sea muy explícita hasta aquí salvaríamos la introducción que culmina también al estilo del maestro:

Y poniendo atajo a los refranes que saltando han ido de la pluma al papel sin el beneplácito de la humilde servidora de ustedes, vamos a desempolvar capítulo de frailes al lado de un milagro. ${ }^{55}$

Ese desempolvar se reitera una y otra vez para aludir a la fuente escrita, los viejos cronicones que, según Cuadros, se centran en los Anales del Curco, de don Diego de Esquivel y $\mathrm{Navia}^{56}$.En esto también Clorinda se pliega a las convenciones del género que exigen remitir al texto para "...provocar en el leçtor la impresión de ser historia" $\mathrm{Si}$ en este último caso la tradición fracasa -desde mi punto de vistase debe a que la Matto pretende aglutinar sin lograrlo dos historias inconexas: capítulo de frailes y el milagro. El resultado será abrupto, deslavazado y sin gracia.

No obstante y "en contra de críticos que lanzan la "moción de censura a la totalidad", pienso que más de la mitad de las tradiciones de Clorinda alcanzan un nivel digno: Testigos sin tacha, El marqués de la viga, El brazo negro del corregidor, Lo de antaño y La antiparras de un escribano en el primer volumen son buenos ejemplos al respecto. Tomemos una breve, El marqués de la viga; ya el exordio que se cuida

\footnotetext{
${ }^{54}$ Clorinda Matto de Turner, Fue un milagro (En: Tradiciones. Tomo 1, op. cit., p. 133).

55 Ibidem, p. 133.

${ }^{56}$ Cfr. Manuel E. Cuadros, Paisaje..., op. cit., p. 89: "para finalizar y como comprobación de haber encontrado la principal fuenté documental de la Sra. Matto diremos que de sus 54 tradiciones, 33 están basadas en pasajes históricos narrados en la obra de Esquivel...". (A continuación da el cuadro con la correspondiente paginación).

${ }^{57}$ Alberto Escobar, Tensión, lenguaje..., op. cit., p. 42.
} 
de apuntalar la fuente histórica atribuyéndosela a Fray Antonio de la Calancha, está teñido por la ironía que no abandonará las tres páginas escasas de la tradición. Ironía compatible, en estas primeras líneas, con la referencia crítica al funcionamiento ambicioso que tiñe la vida pública peruana:

...tomamos el fondo de esta tradición que viene a recordarnos todo lo que hoy se hacer en el Perú para conseguir un puestecito que deje algunas piltrafas de autoridad... ${ }^{58}$

Por aquí se "cuela" la moraleja, elemento característico de la tradición hasta el punto de alejarla del cuento. Moraleja implícita y con más fuerza por ello; como se comprueba por el asalto abrupto con que la Matto sigue adelante: "Y, sin más haches ni cúes, pasamos a relatarla" ${ }^{n 9}$. El relato, muy breve, se apoya en la bisemia y el juego de palabras: Astudillo, joven ansioso de gloria y marquesado, intriga sin éxito para conseguirlo hasta finalizar ahorcándose perdida toda esperanza. La paradoja irónica viene a continuación: “...después de su muerte obtuvo el título que apeteció en vida, siendo mentado con el nombre de el Marqués de la Viga... ${ }^{60}$. Culminada la historia Clorinda hace de nuevo su aparición como narradora:

¿Cuál será la opinión de los diversos candidatos que man-

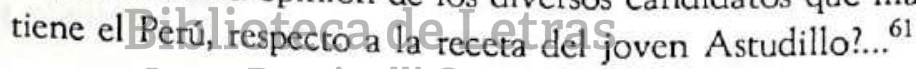

y, traviesa, los incitá La ra búsqueda de de tesoros escondidos:

Ea pues amiguitos: Oropesa no está lejos, como las Marianas del colega Palma.

Tener fe, un chuzo en la mano... y adelante ${ }^{62}$.

El refranero y el lenguaje coloquial está presente, bien es verdad que no tan variopinto y sugeridor como en Palma. Es un elemento que confiere agilidad y popularismo al relato. En el segundo volumen, Un doble y un repique, Las tres hermanas, Moscas y moscardones y Llamada

${ }^{58}$ Clorinda Matto de Turner, El Marqués de la Viga (En: Tradiciones. Tomo I, op. cit., p. 49).

$$
\begin{aligned}
& 59 \mathrm{lbidem}, \mathrm{p} .49 . \\
& { }^{60} \mathrm{Ibidem}, \mathrm{p} .50 . \\
& { }^{61} \mathrm{lbidem}, \mathrm{p} .50 . \\
& { }^{62} \mathrm{lbidem} \text {. p. } 51 .
\end{aligned}
$$


de sepulcro serán, a mi parecer, los ejemplos sostenidos de tradición que merece la pena resaltar. Las relaciones humanas, la picardía para medrar, los personajes del pueblo y la aristocracia de "medio pelo" campean por sus respetos en estas páginas amables; que pueden destilar amargura y deteriorarse si la preocupación de Clorinda por el presente de su país toma esos derroteros.

En resumen, tradición e innovación... moldes ya perfilados en los que se vierten nuevas inquietudes y una fuerte personalidad femenina que no debe ser olvidada.

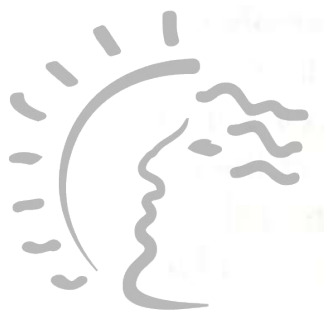

Biblioteca de Letras "Jorge Puccinelli Converso» 